\title{
Challenging High Potential Students In Large Classes: A Hurdles Approach
}

Margaret A. Cleek, (E-mail: cleekma@csus.edu), California State University, Sacramento

\begin{abstract}
A hurdles approach, where qualitatively different expectations are linked to higher grades is suggested as a way of challenging high performing students in large classes with extreme range in ability. Large classes and increasing range in student ability and preparedness as well as diverse student learning styles have made it difficult to design assignments and grading schemes which meet the needs of students in the large class environment. High potential students are particularly underserved in this context. Time considerations are also an issue, as large classes make reading student writing assignments impractical. Most instructors know the value of assignments that challenge students' critical thinking skills, but many can simply no longer handle the workload and thus resort to no papers, no essay exams, and rely on only the multiple-choice exam. It is suggested that setting up a multiple hurdles approach to grading and assignments in classes can address these problems and issues. Properly worked out, this method can provide the challenge your top students' need, the feedback that they deserve, satisfy your need to really challenge students, and address the reality of large classes. This paper outlines how to set up such a multiple hurdles system and make it work.
\end{abstract}

\section{Introduction}

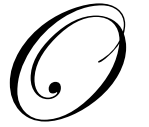

ne of the realities of post-secondary education, especially at public universities, is increased class sizes due to budget considerations. Another fact of life in higher education, again most acutely felt in public institutions, is increased diversity in terms of the educational background and preparedness of students. This is particularly true when universities have basically openenrollment or easy entrance for community college students. Some universities, because of a favorable reputation in certain areas of study, yet unfavorable location in urban areas may actually have a bimodal distribution of students as they attract high performing students because of reputation and low performing students because of location. These conditions present major teaching challenges.

Large classes and increasing range in student ability and preparedness as well as diverse student learning styles have made it difficult to design assignments and grading schemes which meet the needs of students in the large class environment. Time considerations are also an issue, as large classes make the prospect of reading long assignments impractical. Most instructors know the value of written assignments that challenge students' critical thinking skills and develop their written communication skills, but many can simply no longer handle the workload and thus resort to no papers, no essay exams and rely only on the multiple-choice exam. 
While it is not impossible for multiple-choice exams to tap critical thinking skills, the format is more aptly designed to assess content learning. In fact, the multiple choice exam is an excellent methodology to assess understanding of content. Its ease of administration, speed of scoring, and objectivity has made it the method of choice in most settings where large numbers of students are in a class. But this testing methodology primarily depends on recognition. The brightest students correctly surmise that you can study too much for a multiple choice exam and it is better to breeze through and not over think a question. Greater depth of understanding or critical thinking skill can in fact be a liability in multiple choice test taking.

Most professors will be very aware of the limits of multiple-choice testing, but fully embrace it because of practical considerations. It is simple too time consuming to give essay exams or lengthy papers requiring integration skills and critical thinking skills. Basically we have adapted by lowering our expectations, the level of cognitive skill required, and ultimately the standards and quality of higher education.

Coupled with the above is that fact that a large percentage of our students simply do not have the ability to synthesize, integrate and apply course material to unique and challenging problems. In some cases it is not the ability but the motivation that is absent. Students, knowing it is an easier row to hoe will opt for multiple choice tests as an indicator of grades rather than do the difficult work required to analyze and critique information and to express this analysis in an organized and well-written format. The overall result is that students are seldom challenged to display higher order cognitive skills and can spend their entire academic career filling in A, B, C, or ALL OF THE ABOVE bubbles on score sheets.

What is most ironic is that many universities express a great deal of concern about critical thinking skills and written communication skills even as they continue to lower the bar to accommodate decreasing levels of ability and preparedness in college students.

Despite lip service to the needs of bright students, specific ways of challenging and developing high performing students are far and few between. Most learn the grade game early and ace exams but are never challenged to extend their intellectual capabilities. It is suggested that their comfort zone becomes the realm of the multiple choice exam where they know the ropes and can be assured of an A in the course. Most high potential students end up spending most of their time in school working well below their capabilities and never being challenged to develop integrative skills and critical thinking skills. The espoused position is that all students from all economic and cultural backgrounds and all levels of ability and preparedness must reach their full potential. The actual situation is that this possibility has not been extended to our most talented high potential students. They are under challenged and therefore never realize their potential.

\section{What can be done?}

In many situations, professors fully realize that they cannot give challenging assignments which require well-developed integrative and analytical skills to all their students. The time taken to grade this work and give the required feedback for the assignments to be a worthwhile learning experience for the students is prohibitive. In the largely undergraduate institution, graduate assistants with sufficient knowledge of the subject matter to help grade such assignments are not available. Further, the cold hard fact of the situation is that easily $70 \%$ of students in my classes do not have the capability to do this level of work so much time would be spent reading drivel or work lifted from the Internet. 
It is suggested that setting up a multiple hurdles approach to grading and assignments in classes can address these problems and issues. In order to get a grade of $\mathrm{C}$, students are required to pass multiple choice exams. In order to get a grade of $\mathrm{B}$ or $\mathrm{A}$, students are required to do the $\mathrm{C}$ work plus do written assignments of sufficient difficulty, number, and quality to earn the specific grade. Since students selfselect to do the assignments, only high potential students (with a few over-achievers in the mix of course) opt for the demanding A or B workload; teachers are not inundated with large numbers of poor quality papers and good students can be given the feedback and time they deserve. This method has been used successfully over a great many semesters. It has generally worked out that about $10 \%$ of students attempt and succeed at the A workload, $20 \%$ at the B workload, and the remainder opt to attempt C work. If the qualitative expectations and intellectual challenges have been properly gauged, one ends up with a normal curve for the distribution of grades. Since the opportunity to attempt the intellectually challenging work is available to all students, charges of elitism cannot be raised. The needs of ambitious students short on capability can be met and the time is available to give feedback and help to bring their talent and ability in line with their ambition. High ability students actually enjoy the challenge, and many have expressed pride and satisfaction in work well done.

Properly worked out, this method can provide the challenge top students need, the feedback that they deserve, satisfy the professor's need to really challenge students, and address the reality of large classes. The method can also be applied to "two tier" classes where the course contains undergraduate and graduate students and each requires different work load expectations.

\section{How it is put into practice}

Students receive the following information on the syllabus:

\section{COURSE REQUIREMENTS:}

It is important that you attend class, and not attending class will probably affect your test and assignment performance.

You are expected to have read the materials assigned in advance of class so you are prepared for lecture and discussion.

There will be four exams which will be multiple choice. A final will be given at the scheduled exam time and will be cumulative. In order to receive a passing grade (C) you must get $70 \%$ or higher on the semester exams and $50 \%$ or higher on the final. If you miss or fail an exam, you must make arrangements with me and the testing center to retake the exam as many times as it takes to achieve a passing score. By the date of the final you will have to have passed three exams. If you fail the fourth exam, I will give you a $C$ - in the course. If you fail the final, you will fail the course regardless of your performance on the other exams.

I will select questions from the publisher's test bank for exams which correspond to class lecture and discussion.

\section{GRADES:}

Grades are judged against a qualitative and quantitative standard. A curve is not applied and you are not in competition with your classmates for grades. 
To obtain a $\boldsymbol{C}$ in the course you must obtain $70 \%$ or higher on 4 exams and meet the pass requirements for the final. Failed tests can be retaken until a passing grade is earned, but all make-ups and retakes must be completed before the next exam. Exams will be designed to be of a level of difficulty that most students can pass. Since you are not credited with a grade beyond $\boldsymbol{C}$ on an exam, exams are essentially pass/fail. Students who do not do well on multiple choice exams can opt in advance to take a comparable essay exam.

Specific and additional assignments are required to earn a grade of $\boldsymbol{B}$ or $\boldsymbol{A}$ in the course. A grade above $C$ reflects not the quantitative amount of material you have learned and retained for the day of the test, but rather indicates your level of understanding of the material as demonstrated by your ability to integrate and apply the information.

An A means you have the ability to integrate and apply course material and see connections, comparisons and underlying assumptions. You must demonstrate that you can integrate and apply course materials in creative and innovative ways.

A B means that you can make applications of course material and that you can use course material directly as a means to solve problems and explain organizational issues.

A C means that you have passed the exams and thus learned a sufficient quantity of the course material to be judged adequately knowledgeable.

This method of assessing qualitative differences in the grades is consistent with the academic regulations contained in our college catalog.

In order to earn an $\mathbf{A}$, you will have to meet the $\boldsymbol{C}$ requirement and do additional assignments involving case analysis and critiques of readings and film applications at an acceptable level of performance. Work will be returned to be redone if not at the $\boldsymbol{A}$ level or the student may opt for a $\mathbf{B}$ grade or $\mathbf{C}_{+}$ instead. A and $\boldsymbol{B}$ work will require extra time and effort but this will "count" towards your study time for tests as the learning from the assignments should help your test performance. I am totally convinced that students will likely forget material studied for a multiple choice exam, but they will learn and retain material applied to these assignments as well as develop analytical and critical thinking skills.

In order to earn a $\boldsymbol{B}$ you will have to meet the $\boldsymbol{C}$ requirement and do additional assignments of insufficient quality or quantity to earn an A. (For example you may do fewer assignments than required for $\boldsymbol{A}$ work but at $\boldsymbol{A}$ level, or all assignments required for $\boldsymbol{A}$ work but not of sufficient quality to receive an A.) Assignments judged not sufficient for an $\boldsymbol{A}$ or $\boldsymbol{B}$ can be revised and resubmitted.

Additional assignments will be distributed throughout the semester in units. Students are required to hand in assignments prior to exams and turn in all graded assignments again in a portfolio of their work to be handed in before the final. Essentially $\boldsymbol{A}$ and $\boldsymbol{B}$ students will receive specialized attention and an advanced learning format. The extra work should be interesting and well-worth the effort required.

Since this is a new concept for students, there is some anxiety. Ironically the most anxiety is from A students who know they have mastered the multiple choice grading paradigm but fear they will be unable to get high grades in a new system. I generally provide examples of papers and assignments from previous semesters to demonstrate the nature and expectations for the supplemental assignments to earn grades above $\mathrm{C}$. 


\section{The nature of the assignments}

In order to accomplish intended objectives, assignments have to be designed to allow integrative skills to be utilized and to provide opportunity for critical thinking. Students may find assignments where there is no one right answer outside of their comfort zone. Extensive feedback to the students is required and some dialoging between teacher and student takes place in the feedback process. In an effort to both allow students to address topics of interest to them and to allow for variety for the professor reading the work, students are allowed to choose from a number of assignments. Some questions require application of material to existing problems, others are more demanding and require integration and unique and creative application and analysis. Again, since students self-select assignments, you will find that the best students will attempt the more difficult work and the less adept the easier work. This choice on the student's part usually defines the $\mathbf{A}$ or $\mathbf{B}$ grade split.

\section{Examples of Assignments given}

Below, by way of example, are some assignments given in an introductory Organizational Behavior course.

\section{Supplemental Work}

Follow directions given for the assignments. All work will ultimately go in your course portfolio to be turned in the last weeks of the semester. It is suggested that you turn in work on an ongoing basis via email or hard copy throughout the semester. Corrected work goes into the portfolio. Attach e-mail response when given.

Using information from the text and class discussion, answer each of the questions below in a few well-constructed paragraphs.

Why do we get such low levels of predictability when we attempt to understand, predict and control behavior in organizations? If you could enact a "no holds barred" approach to increasing behavioral predictability in the organizational setting what would you do?

Americans are spending more time at work. Several authors have commented that many people are reporting that they find greater satisfaction in their professional lives than in their personal lives. While the home used to be the haven from the workplace, the workplace is now seen by many as the haven from the home. Using your knowledge of organizations, and your own experience, state why this situation might be the case. What changes in organizations and in society have brought about this shift in expectations for needs being met at home or in the workplace?

\section{View one of the films listed below and address the issues in a well-developed paper. Length is not a major criterion of quality, but 1500 words is a good ballpark.}

The basic function of organizations is to continue to survive and to make a profit. Organizations have mission and purpose and they serve the needs of various stakeholders. Ethical conflicts arise when the needs of stakeholders are in conflict or organizations lose sight of their basic mission and purpose. The following docudramas deal with situations where organizational goals are in conflict and ethical dilemmas arise. View one of the following docudramas and state what ethical considerations and organizational goal conflicts arise. Discuss in a well-developed paper your concerns and questions 
regarding these issues. What did you feel, consider and ponder when you observed the events unfold? How should one sort out the issues raised? Where should one's loyalties lie when faced with such a situation? You may go to websites and discuss with friends and classmates but the final product should be yours.

Insider ( 1999)

And the Band Played On (1993)

All the President's Men (1976)

Get on the internet and look up some articles on "globalization.” Read a few that present negative views of globalization and read a few that are positive. In a few well-constructed paragraphs tell what you think.

\author{
Leadership Topics \\ Flight of the Phoenix (1964) \\ Platoon (1986) \\ Seven Samurai (1954) The Magnificent Seven (1960) \\ Lord of the Flies (1990) \\ Crimson Tide (1995) \\ Remember the Titans (2000)
}

Choose one of the films above. From within the framework of one of the theories in your text, compare and contrast the leadership style of two of the principal characters in the film you have chosen. Consider alternate outcomes if the leaders had had different leadership styles.

Organization and Personal Ethics

Fail-Safe (1964)

Rob Roy (1995)

Silkwood (1983)

A Few Good Men (1992)

The Year of Living Dangerously (1983)

Breaker Morant (1980) Rules of Engagement (same story line but not as good a film-1999)

Billy Budd (1962)

Wall Street (1987)

Outland (1981)

Beckett (1964)

Insider (1999)

Wag the Dog (1997)

Choose one of the films above. Discuss your feelings with regard to the ethical issues raised. If the film involves whistle blowing, express your opinion as to the ethical questions and issues of loyalty which this situation presents.

Many of the above films depict situations where someone did the right thing and suffered difficult consequences. Either from the film information or your own experience and recent news events, comment on the following: 
What is meant by the term "scapegoating"? What is the origin of the term? Why might an organization seek to find a scapegoat? Identify at least one situation recently in the news which involved scapegoating.

It has been said that the ethical person is at a disadvantage in a situation because his/her behavior is always predictable. Discuss this opinion and state and defend yours.

In order to give the reader an idea as to the level of thinking, application and integration required in these assignments, here is an example of specific questions assigned for those students addressing the ethical issues contained in the film Breaker Morant.

\section{Breaker Morant}

Discuss the actions taken by Morant's company with regard to their ethics given the situation.

Discuss the actions taken by the British army with regard to Morant. Given their situation were their actions moral?

Situation ethics refers to the idea that there is no absolute morality and that the situational factors have to be taken into account when determining moral behavior. Do you agree? What happens when situation ethics is taken to the extreme? Consider the human capacity for rationalization and discuss the role of cognitive dissonance in your answer.

Find out the origin and meaning of the term "scapegoat". How does scapegoating an individual benefit an organization?

Give a modern example of an organization scapegoating an individual.

\section{Discussion of Assignments}

As can be seen from the sample assignments, these assignments do require application, integration, and critical thinking skills. The assignments are specifically designed to challenge the best students in the class and in fact only high performing students generally attempt the work. Properly constructed in terms of difficulty of assignments, outcomes approximate the normal curve. The author has obtained a near normal curve distribution of A and B grades over many semesters with the remaining 70 percent of students getting $\mathrm{C}$ grades with a few Fs in the mix. As tests are essentially pass/fail, there are no $\mathrm{D}$ grades.

A choice of assignments is given so that students can pick and choose what interests them and students generally do about one quarter of the assignments (8 to 10) in the course of the semester. Work is turned in, graded, and returned to the student in a continuous process. There are no specific due dates for papers other than that papers must be handed in prior to the test administered for that unit. Students are responsible for turning in all graded papers at the end of the semester in a portfolio with a table of contents. Papers are then reviewed and a final grade assigned. Students can get feedback at any time as to what their expected grade will be based on the quality and quantity of work done to date.

I choose films as the focus of many of the assignments because they provide an opportunity to apply the course material and analyze the actions of the characters and this builds application skills and 
the student's ability to recognize organizationally relevant behaviors and responses. There is also a personal mission on my part to expose students to good films.

\section{Targeting High Potential Students}

This process is specifically designed to meet the needs of students who are functioning at an abstract cognitive level and are particularly high potential performers who also have the dedication and motivation to do challenging work to obtain high grades.

It is important that students be challenged to perform at their peak level of performance and even to be given the feedback and assistance to stretch their existing limits. Lowered standards, diverse student ability, and the move to large classes has made it increasingly difficult to meet the needs of all students. Most institutions support and provide help for "at risk" students who are in danger of failing. At the same time these institutions completely fail to recognize that the most "at risk" group may in fact be high performing students who are acing the content based multiple choice exams and are not being challenged in the area of abstract thinking skills.

Some may argue that it is a violation of the concepts of educational equity to provide a different learning experience for one group of students. The argument is that all students should be able to have this experience. In this case the opportunity to perform or attempt to perform at this abstract level of integration and critical analyses is available to all students. The fact that not all students have the capability to do so is a fact beyond the control of the professor or the institution.

The real issue is the issue of meeting students' educational needs. Student needs and talents differ. Developing a process such as the one outlined here is a way of meeting the needs of high performing students capable of abstract thought and critical analysis.

\section{"But I could of [sic] had an A"}

One problem that is encountered when employing this process is that some students will complain that they could have received an A in a traditional non-hurdles class where their grade was based on percentage correct on a multiple choice test. The basic premise of the methodology is that there are qualitative differences between the complexity, cognitive demand, and level of abstraction required to get a grade above C. Mere recognition of the content of the course material is not sufficient for grades above C. What students are actually saying is, "Were it not for my lack of ability and effort, I could of [sic] gotta [sic] A." Many students are incensed by the unfairness of having to display intellectual competence and work for a grade. As far as this author is concerned this only argues more strongly for the need to enact such a process.

\section{Conclusion}

Properly worked out this method can provide the challenge top students need, the feedback that they deserve, satisfy your need to really challenge students, and address the reality of large classes. This method provides an opportunity for high potential students to use their intellectual talents and apply their knowledge, creative ideas and task commitment to assignments designed to challenge and interest them.

It also provides an affirmation to professors that they do in fact have accomplished and interesting students in their courses and allows them to establish a learning relationship and dialog with these students. This is very enriching and rewarding for both student and professor alike. 